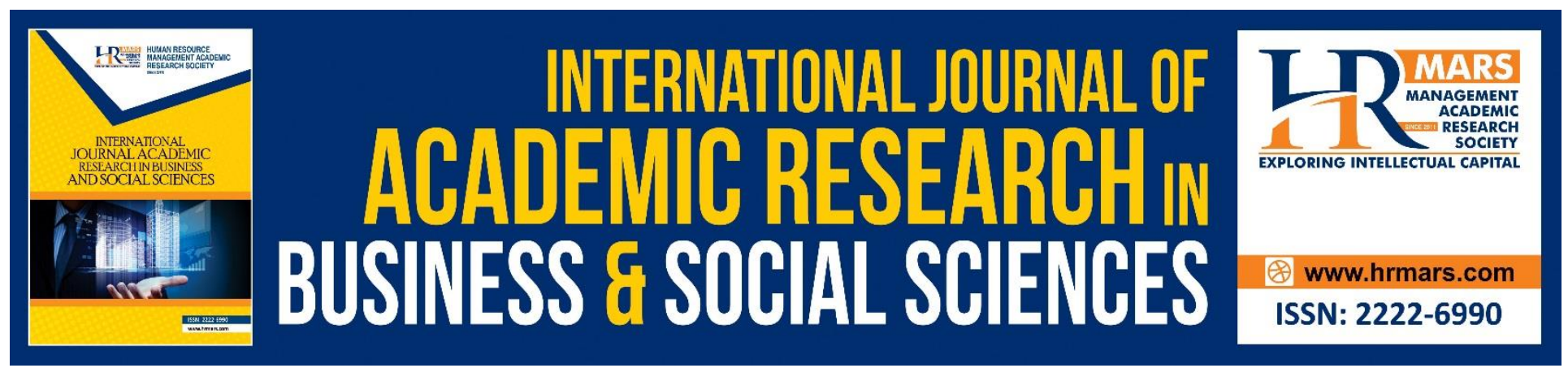

\title{
An Estimation of Value at Risk using GARCH Models for the Conventional and Islamic Stock Market in Malaysia
}

Nor Azliana Aridi, Chin Wen Cheong, Tan Siow Hooi

To Link this Article: http://dx.doi.org/10.6007/IJARBSS/v8-i11/5568

DOI: $10.6007 /$ IJARBSS/v8-i11/5568

Received: 28 Oct 2018, Revised: 25 Nov 2018, Accepted: 30 Nov 2018

Published Online: 04 Dec 2018

In-Text Citation: (Aridi, Cheong, \& Hooi, 2018)

To Cite this Article: Aridi, N. A., Cheong, C. W., \& Hooi, T. S. (2018). An Estimation of Value at Risk using GARCH Models for the Conventional and Islamic Stock Market in Malaysia. International Journal of Academic

Research in Business and Social Sciences, 8(11), 2054-2065.

Copyright: (C) 2018 The Author(s)

Published by Human Resource Management Academic Research Society (www.hrmars.com)

This article is published under the Creative Commons Attribution (CC BY 4.0) license. Anyone may reproduce, distribute, translate and create derivative works of this article (for both commercial and non-commercial purposes), subject to full attribution to the original publication and authors. The full terms of this license may be seen at: $\underline{\text { http://creativecommons.org/licences/by/4.0/legalcode }}$

Vol. 8, No. 11, 2018, Pg. 2054 - 2065

http://hrmars.com/index.php/pages/detail/IJARBSS

JOURNAL HOMEPAGE

Full Terms \& Conditions of access and use can be found at http://hrmars.com/index.php/pages/detail/publication-ethics 


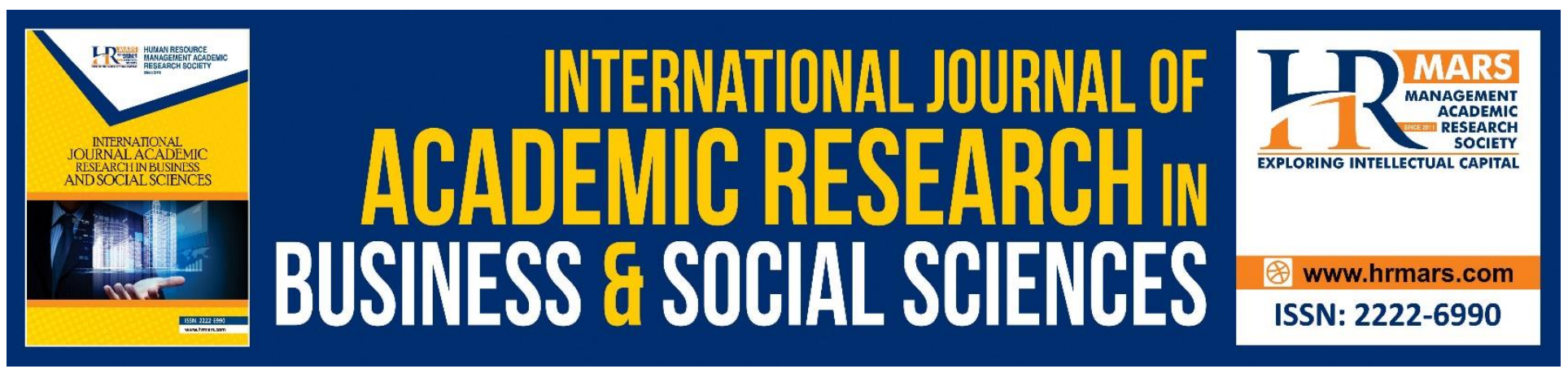

\title{
An Estimation of Value at Risk using GARCH Models for the Conventional and Islamic Stock Market in Malaysia
}

\author{
Nor Azliana Aridi ${ }^{1}$, Chin Wen Cheong ${ }^{2}$, Tan Siow Hooi ${ }^{3}$ \\ ${ }^{1}$ Lecturer, Quantitative Method Unit, Faculty of Management, Multimedia University, 63100 \\ Cyberjaya, Malaysia. \\ ${ }^{2}$ Associate Professor, Department of Mathematics, Xiamen University Malaysia, Jalan Sunsuria, \\ Bandar Sunsuria, Sepang, 43900, Selangor, Malaysia. \\ ${ }^{3}$ Associate Professor, Economics Unit, Faculty of Management, Multimedia University, 63100 \\ Cyberjaya, Malaysia.
}

\begin{abstract}
This study attempts to estimate the value-at-risk ( VaR) to forecast volatility for both conventional and Islamic stock markets in Malaysia. In particular, the purpose of the article is to investigate whether GARCH models are accurate in the evaluation of VaR in emerging stock markets such as Malaysia.The daily return of the conventional $(\mathrm{KLCl})$ and Islamic (FBMS) stock market are analysed for the period 2000 - 2015. The volatility model of $\operatorname{GARCH}(1,1), \operatorname{TGARCH}(1,1)$ and $\operatorname{CGARCH}(1,1)$ with a normal and and student- $t$ distribution are used to model the conditional variance of the stock market returns. The VaR violations of unconditional coverage and the backtesting procedure of Kupiec test are used to check the reliability and accuracy of the volatility model used for both normal and student-t distribution. Based on the Akaike Information Criterion (AIC), the best model for modelling the conventional and Islamic stock market returns is TGARCH $(1,1)$. The backtesting results showed that for all GARCH models used, the normal distribution gives better forecast VaR compared to the student's t distribution.
\end{abstract}

Keywords: Value at Risk, Heavy Tails, GARCH Model, Volatility forecasting, Backtesting

\section{INTRODUCTION}

The modern portfolio theory (MPT) describes the strong relationship between risk and volatility where volatility generates risk associated with the level of dispersion around the mean. In stock market situation, the greater the standard deviation means the greater the stock market dispersion of returns and the greater the risk of the stock market. In other words, the investment is riskier given that the chance to generate excess returns is higher. Therefore, investors who desire for a higher 
return must also prepare for any financial uncertainty. Many previous studies have found models and theories with sophisticated tools that are applicable in measuring and forecasting the stock market risk. One of the common used risk measure is called value at risk (VaR). VaR is used to calculate the maximum financial loss over a specific time frame for a given confidence level by focusing on the estimation of the tails distribution. The primary reason for the underestimation or overestimation of $\mathrm{VaR}$ is because numerous application in the financial field assume that stock market returns are normally distributed while in the real world it is leptokurtosis which exhibit skewness and excess kurtosis. This paper aims to explain the most accurate model to forecast volatility and analyzed the existence of empirical facts in conventional and Islamic market in Malaysia. This paper is organized into seven sections. Section one provides a literature review follows with the methodology used in Section three. Section four discusses the backtesting procedure to check the accuracy of the model used. Next, section five and six provides the descriptive statistics and empirical findings. Finally, section seven concludes the paper.

According to (Goudarzi , 2011), it is essential to continuous study and find out the most accurate measurement of volatility in assets pricing, risk and portfolio management. The application that commonly used in estimating the volatility of stock market returns is the ARCH (GARCH) models. This is due to the capability of these models to capture the characteristics of return series and identify the random movement of stock market prices. Previous studies show no final decision on which one is the best model to forecast volatility. There were studies present a good forecast result based on the simple GARCH $(p, q)$ models but some present that the extensions of GARCH models such as TARCH, EGARCH, APARCH and others provide a better forecast result. In research study done by (Angelidisa, Benosa, \& Degiannakis, 2004) on S\&P 500 Index proves that the combination of a leptokurtic distribution and a simple asymmetric volatility model $\operatorname{AR}(1) \operatorname{EGARCH}(0,1)$, is a good combination in estimating the VaR. Study done by (Smolović, Lipovina-Božović , \& Vujošević, 2017) joined the ARMA model with different specifications of conditional heteroscedasticity models and found that GARCH $(1,1)$, APARCH $(1,1)$ and TGARCH $(1,1)$ are accurate to forecast VaR in emerging stock market. Finding from (Li, Lian , \& Zhang, 2016) presents that $\operatorname{EGARCH~}(1,1)$ is the best forecasted model for Europe Brent crude oil while APARCH $(1,1)$ and GJR-GARCH $(1,1)$ outperformed other GARCH models for West Texas Intermediate (WTI) Cushing crude oil. The forecasting VaR procedure can also be used for the purpose of finding whether Islamic or Conventional stock market are less volatile to the financial uncertainty (Abdrashev, 2016). Study done by (Bhatt \& Sultan, 2012) shows that the Shariah stock market has lower risk premium than the conventional market. In term of the risk premium, (Albaity \& Ahmad, 2011) show that Islamic markets has leverage effects but no risk premium. Another study in Islamic market has been done by (Nasr, Lux , Ajmid, \& Guptae, 2016) on the Dow Jones Islamic Market World Index (DJIM) and the result presents that Markov-switching multifractal (MSM) model outperform the GARCH, FIGARCH and FITVGARCH models in the prediction of VaR.

\section{METHODOLOGY}

The data used are the daily return for FTSE Bursa Malaysia KLCI Index (KLCI), FTSE Bursa Malaysia EMAS Shariah Index (FBMS) from year 2000 - 2015. The continuously compounded rate of return is given by: 


$$
r_{t}=\ln \left(\frac{P_{t}}{P_{t-1}}\right)
$$

Given that $P_{t}$ is the closing price of the security at time t, the stock market returns contain predictable and unpredictable returns as presented in equation (2).

$$
R_{t}=E\left(R_{t} \mid \psi_{t-1}\right)+\varepsilon_{t}
$$

where $\psi_{t-1}$ is all information available at time $t-1$ and $\varepsilon_{t}$ is the unpredictable return written as $\varepsilon_{t}=z_{t} \sigma_{t}, \sigma_{t}$ is the time varying volatility and $z_{t}$ is iid with mean zero and standard deviation one, $z_{t} \square N(0,1)$. In estimating the log return series, the ARCH (q) model which was introduced by (Engle, Autoregressive Conditional Heteroscedasticity with Estimates of the Variance of United Kingdom Inflation, 1982) was used to represents the conditional mean equation thus the conditional variance is expressed as a linear function of the previous $q$ squared innovations written as:

$$
\sigma_{t}^{2}=\omega+\sum_{i=1}^{p} \alpha_{i} \varepsilon_{t-i}^{2}
$$

To make sure that the conditional variance is positive, the parameters must satisfy $\omega>0, \alpha_{i} \geq 0$ and $i=1,2,3 \ldots q$. The higher order $\operatorname{GARCH}(p, q)$ model proposed by (Bollershev, 1986) is generalized from $\mathrm{ARCH}(\mathrm{p})$ model by adding the moving average term as below:

$$
\sigma_{t}^{2}=\omega+\sum_{i=1}^{p} \alpha_{i} \varepsilon_{t-i}^{2}+\sum_{j=1}^{q} \beta_{j} \sigma_{t-i}^{2}
$$

where $\omega>0, \alpha_{i} \geq 0 \beta_{j} \geq 0, i=1,2,3 \ldots q$ and $j=1,2,3, \ldots . p$.

One of the extension model of $\operatorname{GARCH}(p, q)$ that consider the asymmetric effects observed in the data is the Threshold ARCH or TARCH model which has been introduced by (Glosten, Jagannathan, \& Runkle, 1993) and (Zakoian, 1994). The simple model of TARCH $(1,1)$ is defined as:

$$
\begin{aligned}
& \sigma_{t}^{2}=\omega+\beta \sigma_{t-1}^{2}+\alpha \varepsilon_{t-1}^{2}+\gamma \varepsilon_{t-1}^{2} I_{t-1}^{2} \\
& \text { where } \quad I_{t}= \begin{cases}1 & \text { if } \varepsilon_{t-1}<0 \\
0 & \text { otherwise }\end{cases}
\end{aligned}
$$

The TARCH model explains that a response of volatility is influenced by the news information either bad or good news. The bad news $\varepsilon_{t-1}<0$ are followed by higher volatility while the good news $\varepsilon_{t-1}>0$ are followed by the lower volatility. In addition, the $\operatorname{GARCH}(p, q)$ model are also arguably does not consider the trend and seasonality in stock prices. To capture the volatility dynamics of time varying persistence, the component GARCH model (CGARCH) has been introduced by (Engle \& Lee, 1999) and (Ding \& Granger, 1996) to capture the trend and seasonality in longer time period. The simplified CGARCH $(1,1)$ equation is provided as below:

$$
\sigma_{t}^{2}=\sigma_{L R, t}^{2}+\sigma_{S R, t}^{2}
$$

where 
INTERNATIONAL JOURNAL OF ACADEMIC RESEARCH IN BUSINESS AND SOCIAL SCIENCES

Vol. 8, No. 11, Nov, 2018, E-ISSN: 2222-6990 @ 2018 HRMARS

$$
\begin{gathered}
\sigma_{L R, t}^{2}=\omega+\gamma_{L R 1} \sigma_{L R, t-1}^{2}+\gamma_{L R 2}\left(z_{t-1}^{2}-\sigma_{t-2}^{2}\right) \\
\sigma_{S R, t}^{2}=\gamma_{S R 1} \sigma_{S R, t-1}^{2}+\gamma_{S R 2}\left(z_{t-1}^{2}-\sigma_{t-1}^{2}\right)
\end{gathered}
$$

Previous study done by (Engle, Autoregressive Conditional Heteroscedasticity with Estimates of the Variance of United Kingdom Inflation, 1982) assumed that the distribution was normal. Subsequently, (Bollershev, 1986) has introduced the standardized t-distribution with degrees of freedom, $(v-2)$ which given as:

$$
D\left(z_{t} ; v\right)=\frac{\Gamma((v+1) / 2)}{\Gamma(v / 2) \sqrt{\pi(v-2)}}\left(1+\frac{z_{t}^{2}}{v-2}\right)^{-\frac{v+1}{2}}
$$

where $\Gamma(v)=\int_{0}^{\infty} e^{-x} x^{v-1} d x$ is the gamma function and $v$ is the parameter that represents the thickness of the tail distribution. If $v>4$, the conditional kurtosis is equal to $3(v-2) /(v-4)$ which above the usual normal value of 3 . For the standardized normal distribution series $\varepsilon_{t}$, the estimation of VaR at $95 \%$ and $99 \%$ confidence level and for one-step ahead forecast horizon is computed as:

$$
\begin{aligned}
& \operatorname{VaR}_{5 \%}=\widehat{r}_{t}(1)-1.65 \hat{\sigma}_{t}(1) \\
& \operatorname{VaR}_{1 \%}=\widehat{r}_{t}(1)-2.33 \hat{\sigma}_{t}(1)
\end{aligned}
$$

For the standardized student-t distribution series $\varepsilon_{t}$, the estimation of $\mathrm{VaR}$ at $95 \%$ and $99 \%$ confidence level and for one-step ahead forecast horizon is computed as:

$$
\operatorname{VaR}_{5 \% / 1 \%}=\widehat{r}_{t}(1)-t_{v}^{*} \widehat{\sigma}_{t}(1)
$$

where $t_{v}^{*}=\frac{t_{v}(1-\alpha)}{\sqrt{\frac{v}{v-2}}}$ and $t_{v}(1-\alpha)$ is the correlated critical value of $(1-\alpha)$ quantile, $v$ degrees of freedom from t-distribution. The backtesting procedure was done after VaR estimation to test the reliability and accuracy of the model used. The procedure is important to identify the amount of losses predicted by VaR model is accurate by comparing the forecasted VaR with the actual realized returns generated from the historical stock prices observation. According to (Danielsson, 2011) the VaR limit is said to have been violated given that a financial loss on a particular day exceeds the forecasted VaR as formulated below:

$$
\eta_{t}=\left\{\begin{array}{lll}
1 & \text { if } & r_{t} \leq-V a R_{t} \\
0 & \text { if } & r_{t}>-V a R_{t}
\end{array}\right.
$$

The violation ratio (VR) is calculated by dividing the observed number of VaR violations and the expected number of VaR violations. The expected number of violations is calculated as $p \times w_{t}$ where $p$ is the 
respective probability used and $w_{t}$ is the number of observation used to forecast risk. The VaR model is said to be under forecasts risk if the violation ratio is greater than one while on the other hand if it is smaller than one the VaR model is said to be over forecasts risk. To confirm whether any other value is statistically significant other than expected $V R=1$, the following guideline explained by (Danielsson, 2011) to explain the accuracy of the selected VaR model. The first one is if the value of the $V R \in[0.8$, 1.2] the forecast is good. If $V R<0.5$ or $V R>1.5$ the model is imprecise and if $V R<0.3$ or $V R>2$ the model is not good. Another process of backtesting involved unconditional coverage tests for the correct number of exceedances is the Proportion of Failure test (POF-test) which also known as Kupiec test. Let $N=\sum_{t=1}^{T} I_{t}$ be the number of days over a time period $\mathrm{T}$ when the portfolio loss was greater than the VaR estimate given by :

$$
I_{t}=\left\{\begin{array}{lll}
1 & \text { if } & r_{t, t+1} \geq-V a R_{t} \\
0 & \text { if } & r_{t, t+1}<V a R_{t}
\end{array}\right.
$$

The unconditional coverage for $95 \%$ confidence regions introduced by (Kupiec, 1995) are presented in Table (i). The failure rate recorded follows a binomial distribution given that the number of exceptions in the sample is $\mathrm{N}$ and the failure rate is $\mathrm{N} / \mathrm{T}$. The no rejection region in Table (i) are defined by the appropriate log-likelihood ratio statistics:

$$
L R_{P O F}=-2 \ln \left[(1-p)^{(T-x)} p^{x}\right]+2 \ln \left[\left(1-\frac{x}{T}\right)^{(T-x)}\left(\frac{x}{t} T\right)^{x}\right]
$$

The Kupiec test is asymptotically distributed Chi-square with degree of freedom equal to one.

Table (i)

Unconditional Coverage for 95\% Nonrejection Region

\begin{tabular}{|r|r|c|c|c|}
\hline \multirow{2}{*}{$p$} & \multirow{2}{*}{$c$} & \multicolumn{3}{|c|}{ Nonrejection Region } \\
\cline { 3 - 5 } & & $\mathrm{T}=252$ & $\mathrm{~T}=510$ & $\mathrm{~T}=1000$ \\
\hline 0.01 & $99 \%$ & $\mathrm{~N}<7$ & $1<\mathrm{N}<11$ & $4<\mathrm{N}<17$ \\
\hline 0.03 & $97.50 \%$ & $2<\mathrm{N}<12$ & $6<\mathrm{N}<21$ & $15<\mathrm{N}<36$ \\
\hline 0.05 & $95 \%$ & $6<\mathrm{N}<20$ & $16<\mathrm{N}<36$ & $37<\mathrm{N}<65$ \\
\hline 0.08 & $92.50 \%$ & $11<\mathrm{N}<28$ & $27<\mathrm{N}<51$ & $59<\mathrm{N}<92$ \\
\hline 0.1 & $90 \%$ & $16<\mathrm{N}<36$ & $38<\mathrm{N}<65$ & $81<\mathrm{N}<120$ \\
\hline
\end{tabular}

\section{RESULTS}

\section{DATA \& DESCRIPTIVE STATISTICS}

The data consist of approximately 3935 daily returns of FTSE Bursa Malaysia KLCI Index (KLCI) and FTSE Bursa Malaysia EMAS Shariah Index (FBMS) during trading day's period of $2000-2015$. 
INTERNATIONAL JOURNAL OF ACADEMIC RESEARCH IN BUSINESS AND SOCIAL SCIENCES Vol. 8, No. 11, Nov, 2018, E-ISSN: 2222-6990 @ 2018 HRMARS

Table (ii)

Descriptive Statistics of the daily log returns for the period 2000-2015

\begin{tabular}{|l|c|c|}
\hline Statistics & KLCI & FBMS \\
\hline Mean & -0.000144 & -0.000138 \\
\hline Median & -0.0004 & -0.00038 \\
\hline Maximum & 0.10493 & 0.11986 \\
\hline Minimum & -0.04403 & -0.048 \\
\hline Std. Dev. & 0.008509 & 0.008977 \\
\hline Skewness & 0.980215 & 1.19813 \\
\hline Kurtosis & 14.28124 & 17.24644 \\
\hline Jarque-Bera & 21496.51 & 34218.6 \\
\hline Probability & 0 & 0 \\
\hline Observations & 3935 & 3935 \\
\hline
\end{tabular}

Both conventional and Islamic time series shows signs of volatility clustering as shown in Figure (i). The tendency of large changes in prices shows that there is persistence in the magnitude of the price changes. Based on the unconditional variance of standard deviation from Table (ii), FBMS has the highest volatility followed by $\mathrm{KLCl}$. For normality test, the series must have skewness equal to zero, kurtosis coefficient equal to three and has probability of Jacque-Bera greater than 0.05 to meet the requirement of normal distribution. Table (ii) presented that $\mathrm{KLCl}$ and $\mathrm{FBMS}$ have positive skewness which showed that the returns are inclined to the right side of the distribution. The kurtosis value represents that the return distributions of $\mathrm{KLCl}$ and FBMS the thickness in the tail of $\mathrm{KLCl}$ and FBMS feature leptokurtic distribution due to coefficients larger than three. Finally, the Jacque-Bera $p$-value show $\mathrm{KLCl}$ and FBMS Index violated the normal distribution criteria.
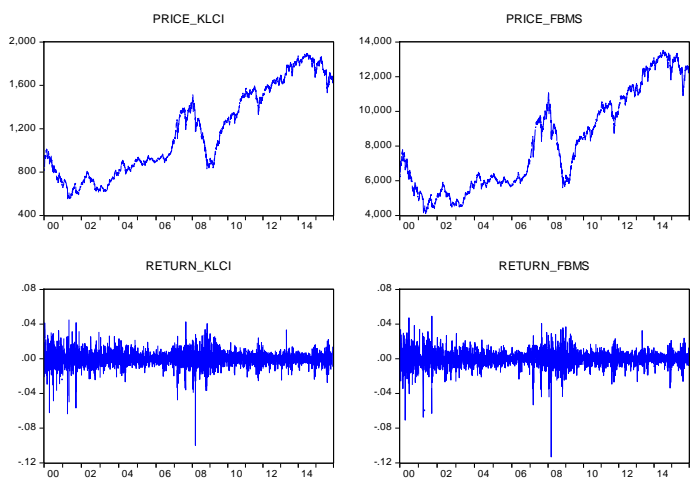

Fig. (i) Continuous Compounded Daily Returns of KLCl and FBMS Index from 2000-2015

\section{EMPIRICAL RESULTS}

From Figure (i), the existence of volatility clustering emerged due to the frequent changes of stock returns show unpredictability of volatility. Table (iii) shows the value of Akaike information criterion (AIC) and Schwarz information criterion (SIC) for $\mathrm{KLCl}$ both conventional and Islamic market for normal and student's t distribution. Based on the information criteria of the Akaike Information Criteria (AIC) and Schwarz Information Criteria (SIC) presented in Table (iii), TARCH $(1,1)$ is the best 
INTERNATIONAL JOURNAL OF ACADEMIC RESEARCH IN BUSINESS AND SOCIAL SCIENCES

Vol. 8, No. 11, Nov, 2018, E-ISSN: $2222-6990$ @ 2018 HRMARS

estimated model for modelling the logarithmic return series of both $\mathrm{KLCl}$ and FBMS Index since it has the lowest values of AIC and SIC.

Table (iii)

Criteria for Model Selection

\begin{tabular}{|c|c|c|c|}
\hline \multirow{2}{*}{ Index } & \multirow{2}{*}{ Distribution } & \multicolumn{2}{|c|}{ Model selection } \\
\hline & & AIC & $\mathrm{SIC}$ \\
\hline \multirow{6}{*}{$\mathrm{KLCl}$} & GARCH $(1,1)-n$ & -7.0453 & -7.0373 \\
\hline & GARCH $(1,1)-\mathrm{t}$ & -7.1143 & -7.1048 \\
\hline & $\operatorname{TARCH}(1,1)-n$ & -7.0541 & -7.0446 \\
\hline & TARCH $(1,1)-\mathrm{t}$ & -7.1182 & -7.1071 \\
\hline & CGARCH $(1,1)-n$ & -7.0672 & -7.0545 \\
\hline & CGARCH $(1,1)$-t & -7.1141 & -7.0997 \\
\hline \multirow{6}{*}{ FBMS } & GARCH $(1,1)-n$ & -6.9709 & -6.9629 \\
\hline & $\operatorname{GARCH}(1,1)-\mathrm{t}$ & -7.0548 & -7.0452 \\
\hline & $\operatorname{TARCH}(1,1)-n$ & -6.9808 & -6.9713 \\
\hline & $\operatorname{TARCH}(1,1)-\mathrm{t}$ & -7.0595 & -7.0484 \\
\hline & $\operatorname{CGARCH}(1,1)-n$ & -6.9867 & -6.9739 \\
\hline & CGARCH $(1,1)-\mathrm{t}$ & -7.0534 & -7.0391 \\
\hline
\end{tabular}

Table (iv)

Parameter Estimates of the GARCH Family Model for KLCI Index (2000-2015)

\begin{tabular}{|c|c|c|c|c|c|c|}
\hline \multirow{3}{*}{ Parameter } & \multicolumn{6}{|c|}{$\mathrm{KLCl}$} \\
\hline & \multicolumn{2}{|c|}{$\operatorname{GARCH}(1,1)$} & \multicolumn{2}{|c|}{$\operatorname{TARCH}(1,1)$} & \multicolumn{2}{|c|}{ CGARCH $(1,1)$} \\
\hline & normal & stud t & normal & stud $t$ & normal & stud $t$ \\
\hline C & $4.00 \mathrm{E}-04$ & 3.70E-04 & $2.46 \mathrm{E}-04$ & $2.89 \mathrm{E}-04$ & $3.75 \mathrm{E}-04$ & $3.66 \mathrm{E}-04$ \\
\hline $\operatorname{AR}(1)$ & 0.1669 & 0.1344 & 0.1706 & 0.1371 & 0.1653 & 0.1424 \\
\hline$\omega$ & $1.02 \mathrm{E}-06$ & $1.13 \mathrm{E}-06$ & 1.17E-06 & 1.19E-06 & 4.19E-05 & $1.12 \mathrm{E}-04$ \\
\hline$\alpha$ & 0.1190 & 0.1208 & 0.0727 & 0.0825 & 0.0983 & 0.0022 \\
\hline$\beta$ & 0.8727 & 0.8687 & 0.8725 & 0.8682 & 0.7275 & -0.9927 \\
\hline$\gamma$ & - & - & 0.0893 & 0.0745 & 0.0181 & 0.1226 \\
\hline$\rho$ & - & - & & - & 0.9965 & 0.9904 \\
\hline $\mathrm{v}$ & - & 5.6620 & - & 5.8001 & - & 5.7184 \\
\hline \multirow{2}{*}{ resQ-(12) } & 9.9926 & 17.5290 & 11.0080 & 18.1160 & 9.9810 & 17.4540 \\
\hline & 0.5310 & 0.0930 & 0.4430 & 0.0790 & 0.5321 & 0.0950 \\
\hline res squ & 12.8840 & 12.0170 & 12.4290 & 12.1980 & 12.1120 & 11.8360 \\
\hline Q-(12) & 0.3780 & 0.4440 & 0.4120 & 0.4300 & 0.4370 & 0.4590 \\
\hline \multirow{2}{*}{$\mathrm{ARCH}(12)$} & 1.0013 & 0.9384 & 0.9891 & 0.9780 & 0.9680 & 0.9209 \\
\hline & 0.4447 & 0.5069 & 0.4564 & 0.4673 & 0.4772 & 0.5247 \\
\hline
\end{tabular}


INTERNATIONAL JOURNAL OF ACADEMIC RESEARCH IN BUSINESS AND SOCIAL SCIENCES Vol. 8, No. 11, Nov, 2018, E-ISSN: 2222-6990 @ 2018 HRMARS

Table (v)

Parameter Estimates of the GARCH Family Model for FBMS Index (2000-2015)

\begin{tabular}{|c|c|c|c|c|c|c|}
\hline \multirow{3}{*}{ Parameter } & \multicolumn{6}{|c|}{ FBMS } \\
\hline & \multicolumn{2}{|c|}{$\operatorname{GARCH}(1,1)$} & \multicolumn{2}{|c|}{$\operatorname{TARCH}(1,1)$} & \multicolumn{2}{|c|}{ CGARCH $(1,1)$} \\
\hline & normal & stud $t$ & normal & stud $t$ & normal & stud $t$ \\
\hline C & 4.36E-04 & 3.85E-04 & $2.65 \mathrm{E}-04$ & $3.05 \mathrm{E}-04$ & 4.59E-04 & 3.74E-04 \\
\hline $\operatorname{AR}(1)$ & 0.163 & 0.131 & 0.162 & 0.134 & 0.151 & 0.130 \\
\hline$\omega$ & $9.95 \mathrm{E}-07$ & $1.09 \mathrm{E}-06$ & $1.07 \mathrm{E}-06$ & 1.17E-06 & $4.79 \mathrm{E}-05$ & $1.25 \mathrm{E}-04$ \\
\hline$\alpha$ & 0.127 & 0.112 & 0.076 & 0.074 & 0.058 & 0.012 \\
\hline$\beta$ & 0.869 & 0.879 & 0.871 & 0.876 & 0.785 & -0.519 \\
\hline$\gamma$ & - & - & 0.094 & 0.080 & 0.023 & 0.114 \\
\hline$\rho$ & - & - & - & - & 0.997 & 0.991 \\
\hline $\mathrm{v}$ & - & 5.066 & - & 5.184 & - & 5.079 \\
\hline \multirow{2}{*}{ resQ-(12) } & 18.349 & 26.039 & 19.449 & 25.662 & 20.429 & 26.494 \\
\hline & 0.074 & 0.006 & 0.054 & 0.007 & 0.040 & 0.005 \\
\hline res squ & 7.931 & 7.276 & 7.316 & 6.423 & 3.597 & 7.258 \\
\hline Q-(12) & 0.791 & 0.839 & 0.836 & 0.893 & 0.990 & 0.840 \\
\hline \multirow{2}{*}{ ARCH (12) } & 0.628 & 0.563 & 0.603 & 0.517 & 0.295 & 0.563 \\
\hline & 0.820 & 0.873 & 0.603 & 0.905 & 0.990 & 0.873 \\
\hline
\end{tabular}

Table (vi)

Backtesting results using Violation Ratio for $\mathrm{KLCl}$ and FBMS

\begin{tabular}{|c|c|c|c|}
\hline \multirow{2}{*}{ Index } & \multirow{2}{*}{ Model } & \multicolumn{2}{|c|}{ Violation ratios } \\
\hline & & $95 \%$ & $99 \%$ \\
\hline \multirow{6}{*}{$\mathrm{KLCl}$} & $\operatorname{GARCH}(1,1)-\mathrm{n}$ & 0.8943 & 1.626 \\
\hline & $\operatorname{GARCH}(1,1)-\mathrm{t}$ & 0.4065 & 0 \\
\hline & $\operatorname{TARCH}(1,1)-\mathrm{n}$ & 0.813 & 1.626 \\
\hline & $\operatorname{TARCH}(1,1)-\mathrm{t}$ & 0.4065 & 0 \\
\hline & $\operatorname{CGARCH}(1,1)-\mathrm{n}$ & 1.3008 & 1.2195 \\
\hline & CGARCH $(1,1)-t$ & 0.4065 & 0 \\
\hline \multirow{6}{*}{ FBMS } & $\operatorname{GARCH}(1,1)-n$ & 1.1382 & 0.813 \\
\hline & $\operatorname{GARCH}(1,1)-\mathrm{t}$ & 0.4878 & 0 \\
\hline & $\operatorname{TARCH}(1,1)-\mathrm{n}$ & 0.8943 & 0.4065 \\
\hline & $\operatorname{TARCH}(1,1)-\mathrm{t}$ & 0.3252 & 0 \\
\hline & $\operatorname{CGARCH}(1,1)-\mathrm{n}$ & 0.9756 & 1.2195 \\
\hline & $\operatorname{CGARCH}(1,1)-t$ & 0.4878 & 0 \\
\hline
\end{tabular}

Table (vii)

Backtesting results using Kupiec Test for $\mathrm{KLCl}$ and FBMS

\begin{tabular}{|c|c|c|c|c|c|}
\hline \multirow{4}{*}{ Index } & \multirow{4}{*}{ Model } & \multicolumn{4}{|c|}{ Binomial Test } \\
\hline & & \multicolumn{2}{|c|}{$95 \%$} & \multicolumn{2}{|c|}{$99 \%$} \\
\hline & & \multirow{2}{*}{$\mathrm{N}$} & Test & \multirow{2}{*}{$\mathrm{N}$} & Test \\
\hline & & & Stats & & Stats \\
\hline \multirow{6}{*}{$\mathrm{KLCl}$} & GARCH $(1,1)-n$ & 11 & -0.38 & 4 & 0.987 \\
\hline & $\operatorname{GARCH}(1,1)-\mathrm{t}$ & 5 & -2.136 & 0 & -1.576 \\
\hline & $\operatorname{TARCH}(1,1)-\mathrm{n}$ & 10 & -0.673 & 4 & 0.987 \\
\hline & $\operatorname{TARCH}(1,1)-\mathrm{t}$ & 5 & -2.136 & 0 & -1.576 \\
\hline & $\operatorname{CGARCH}(1,1)-\mathrm{n}$ & 16 & 1.082 & 3 & 0.346 \\
\hline & $\operatorname{CGARCH}(1,1)-\mathrm{t}$ & 5 & -2.136 & 0 & -1.576 \\
\hline \multirow{6}{*}{ FBMS } & GARCH $(1,1)-n$ & 14 & 0.497 & 2 & -0.295 \\
\hline & $\operatorname{GARCH}(1,1)-\mathrm{t}$ & 6 & -1.843 & 0 & -1.576 \\
\hline & $\operatorname{TARCH}(1,1)-\mathrm{n}$ & 11 & -0.38 & 1 & -0.936 \\
\hline & $\operatorname{TARCH}(1,1)-\mathrm{t}$ & 4 & -2.428 & 0 & -1.576 \\
\hline & $\operatorname{CGARCH}(1,1)-\mathrm{n}$ & 12 & -0.088 & 3 & 0.346 \\
\hline & $\operatorname{CGARCH}(1,1)-\mathrm{t}$ & 6 & -1.843 & 0 & -1.576 \\
\hline
\end{tabular}


INTERNATIONAL JOURNAL OF ACADEMIC RESEARCH IN BUSINESS AND SOCIAL SCIENCES

Vol. 8, No. 11, Nov, 2018, E-ISSN: 2222-6990 @ 2018 HRMARS

Table (viii)

Backtesting results using Kupiec Test for $\mathrm{KLCl}$ and FBMS

\begin{tabular}{|c|c|c|c|c|c|}
\hline \multirow{4}{*}{ Index } & \multirow{4}{*}{ Model } & \multicolumn{4}{|c|}{ Unconditional Coverage } \\
\hline & & \multicolumn{2}{|c|}{$95 \%$} & \multicolumn{2}{|c|}{$99 \%$} \\
\hline & & \multirow{2}{*}{$\mathrm{N}$} & Test & \multirow{2}{*}{$\mathrm{N}$} & Test \\
\hline & & & Stats & & Stats \\
\hline \multirow{6}{*}{$\mathrm{KLCl}$} & $\operatorname{GARCH}(1,1)-\mathrm{n}$ & 11 & 0.1497 & 4 & 0.8188 \\
\hline & $\operatorname{GARCH}(1,1)-t$ & 5 & 5.8241 & 0 & NA \\
\hline & TARCH $(1,1)-n$ & 10 & 0.4823 & 4 & 0.8188 \\
\hline & $\operatorname{TARCH}(1,1)-t$ & 5 & 5.8241 & 0 & NA \\
\hline & $\operatorname{CGARCH}(1,1)-n$ & 16 & 1.0746 & 3 & 0.1119 \\
\hline & $\operatorname{CGARCH}(1,1)-\mathrm{t}$ & 5 & 5.8241 & 0 & NA \\
\hline \multirow{6}{*}{ FBMS } & $\operatorname{GARCH}(1,1)-n$ & 14 & 0.2372 & 2 & 0.0928 \\
\hline & $\operatorname{GARCH}(1,1)-\mathrm{t}$ & 6 & 4.1542 & 0 & NA \\
\hline & $\operatorname{TARCH}(1,1)-\mathrm{n}$ & 11 & 0.1497 & 1 & 1.1284 \\
\hline & $\operatorname{TARCH}(1,1)-t$ & 4 & 7.9049 & 0 & NA \\
\hline & $\operatorname{CGARCH}(1,1)-\mathrm{n}$ & 12 & 0.0078 & 3 & 0.1119 \\
\hline & $\operatorname{CGARCH}(1,1)-\mathrm{t}$ & 6 & 4.1542 & 0 & NA \\
\hline
\end{tabular}

\section{DISCUSSION}

To check the model accuracy, the backtesting procedures of violation ratio, Binomial test and Kupiec test has been done to compare the forecast VaR with the ex-post realized returns for all models. The procedure of violation ratio is occurred when financial losses exceed the previous day's VaR. By using a sample of $\mathrm{T}=\mathbf{2 4 6}$ days observations, the violation ratios for both conventional and Islamic indices based on $95 \%$ and $99 \%$ confidence level are considered as shown in Table (vii). The expected number of violations for $95 \%$ is calculated by using the formula explained in [6] thus, for $95 \%$ confidence level, the expected number of violation is $0.05 \times 246=12.3$ while for $99 \%, 0.01 \times 246=2.46$. By using $95 \%$ confidence level, the $\mathrm{KLCl}$ Index results exhibit that all model is said to be over forecasts risk because the value is smaller than 1 except for the $\operatorname{CGARCH}(1,1)$ normal distribution model. However, for student's $t$ distribution, all models are over forecasts risk. Different with Islamic Index (FBMS), all models over forecasts risk except for the $\operatorname{GARCH}(1,1)$ normal distribution model. For $\mathrm{KLCl}$ Index, the $\operatorname{GARCH}(1,1)$ and TARCH $(1,1)$ with normal distribution displays the forecast model is good because the value of the $\operatorname{VR} \in[0.8,1.2]$. For FBMS Index, the $\operatorname{TARCH}(1,1)$ and $\operatorname{CGARCH}(1,1)$ normal distribution showed the forecast model is good. All model with student's t distribution for both $\mathrm{KLCl}$ and FBMS Index showed that the model is imprecise because VR<0.5 or VR $>1.5$. Based on the Binomial test, the result show that for $5 \%$, the critical values used are \pm 1.96 while for $1 \%$ the values are \pm 2.57 . Based on $95 \%$ confidence level, the forecast VaR for all models with normal distribution are located under the non-rejection area thus the null hypothesis is accepted. However, for student's $t$ distribution, the forecast $\mathrm{VaR}$ in under rejection area which reject the null hypothesis. The result for 99\% confidence level shows that all test statistic values are located under the non-rejection area thus the null hypothesis is accepted. The results of the Kupiec test are presented in Table (viii). The forecasted value of VaR for $95 \%$ confidence level with normal distribution gives good results where $\mathrm{VaR}$ forecast values are below than $\chi^{2}=3.841$ thus accepting the null hypothesis of correct unconditional coverage. Furthermore, for student's $t$ distribution, the null hypothesis of correct unconditional coverage is rejected. The number of exception, $\mathrm{N}$ for student's t distribution is far too small compared to the expected excesses 12.3. Additional, for $99 \%$ confidence level, the models with normal distribution yield satisfactory results with forecast VaR less than $\chi^{2}=6.635$ however for 
INTERNATIONAL JOURNAL OF ACADEMIC RESEARCH IN BUSINESS AND SOCIAL SCIENCES

Vol. 8, No. 11, Nov, 2018, E-ISSN: 2222-6990 @ 2018 HRMARS

student's t distribution, the result indicate NA (not applicable) due to insufficient number of convergences.

\section{CONCLUSION}

Based on the descriptive statistics result, both markets feature leptokurtic distribution with skewness skewed to the right and heavy tails. The TARCH $(1,1)$ is the best fitted models based on the values of $\mathrm{AIC}$ and SIC. The backtesting result of violation ratio show that for $95 \%$ confidence level, the $\mathrm{KLCl}$ and FBMS Index show the result of over forecasts risk for both normal and student's t. The TARCH $(1,1)$ model with normal distribution displays as the good forecast model for both conventional and Islamic Index based on the violation value VR $\in[0.8,1.2]$. The backtesting result of Kupiec test also show that all models with normal distribution passed the Kupiec test at $95 \%$ and $99 \%$ confidence level. However, for student's t distribution, the result does not accept the null hypothesis of correct unconditional coverage. The Kupiec test results for student's $t$ distribution of both markets indicate NA (not applicable) due to insufficient number of convergences. The good forecast result for TARCH $(1,1)$ model based on the violation ratio, Binomial test and Kupiec test are consistent with the AIC and SIC criteria to be the most accurate model to forecast VaR. Based on the given result, $95 \%$ confidence level yielded a good forecast result but when the confidence level is increased to $99 \%$, a small sample size may lead to lack of convergence in estimating the number of exceptions. The normal distribution provides a good forecast VaR than student's $t$ distribution. To overcome the problem of difficulty of VaR models in estimating the heavy tailed of the return distribution, further study will be focuses on the heavy tails distribution by comparing GARCH models and the conditional Extreme Value Theory (EVT) specifications to improve the VaR forecasting performance.

\section{References}

Abdrashev, N. (2016). Comparison of Islamic and conventional bank stocks by Value-At-Risk method. Journal of Insurance and Financial Management, 19-31.

Albaity, M., \& Ahmad, R. (2011). Return performance, leverage effect, and volatility spillover in. Investment Management and Financial Innovations, 161-171.

Angelidisa, T., Benosa, A., \& Degiannakis, S. (2004). The use of GARCH models in VaR estimation. Statistical Methodology, 105-128.

Bhatt, V., \& Sultan, J. (2012). Leverage Risk, Financial Crisis, and Stock Returns: A Comparison among Islamic, Conventional, and Socially Responsible Stocks. Islamic Economic Studies, 87143.

Bollershev, T. (1986). Generalized Autoregressive Conditional Heteroskedasticity. Journal of Econometrics, 307-327.

Danielsson, J. (2011). Financial Risk Forecasting: The Theory and Practice of Forecasting Market Risk with Implementation in R and Matlab. London: Wiley.

Ding, Z., \& Granger, C. (1996). Modeling Volatility Persistence of Speculative Returns: A New Approach. Journal of Ecometrics, 185-215.

Engle, R. F. (1982). Autoregressive Conditional Heteroscedasticity with Estimates of the Variance of United Kingdom Inflation. Econometrica, 987-1007. 
Engle, R. F., \& Lee , G. (1999). A Permanent and Transitory Component Model of Stock Return Volatility in R.F. Engle and H. White (eds.), Cointegration, Causality, and Forecasting: A Festschrift in Honor of Clive W.J. Granger. Oxford University Press, 475-497.

Glosten, L., Jagannathan, R., \& Runkle, D. (1993). On the Relation between the Expected Value and the Volatility of the Nominal Excess Return on Stocks. The Journal of Finance, 1779-1801.

Goudarzi , H. (2011). Modeling Asymmetric Volatility in the Indian Stock Market. International Journal of Business and Management , 221-231.

Kupiec, P. H. (1995). Techniques for Verifying the Accuracy of Risk Measurement Models. The Jounal of Derivatives, 73-84.

Li, Y.-X., Lian , J.-G., \& Zhang, H.-K. (2016). Forecast and Backtesting of VAR Models in Crude Oil Market. Journal of Statistics and Mathematical Sciences, 131-140.

Nasr, A. B., Lux , T., Ajmid, A., \& Guptae, R. (2016). Forecasting the volatility of the Dow Jones Islamic Stock Market Index: Long memory vs. regime switching. International Review of Economics and Finance, 559-571.

Smolović, J. C., Lipovina-Božović , M., \& Vujošević, S. (2017). GARCH models in value at risk estimation:empirical evidence from the Montenegrin stock exchange. Economic ResearchEkonomska Istraživanja, 477-498.

Zakoian, J. M. (1994). Threshold heteroskedastic models. Journal of Economic Dynamics and Control, 931-955. 